\title{
MEKC of desmosine and isodesmosine in urine of chronic destructive lung disease patients
}

\author{
S. Viglio*, P. Iadarola*, A. Lupi*,**, R. Trisolini**, C. Tinelli***, B. Balbi ${ }^{+}$, V. Grassi ${ }^{++}$, \\ D. Worlitzsch ${ }^{++}$, G. Döring ${ }^{+++}$, F. Meloni**, K.C. Meyer" ${ }^{\#}$, L. Dowson ${ }^{*}$, S.L. Hill", \\ R.A. Stockley", M. Luisetti**
}

MEKC of desmosine and isodesmosine in urine of chronic destructive lung disease patients. S. Viglio, P. Iadarola, A. Lupi, R. Trisolini, C. Tinelli, B. Balbi, V. Grassi, D. Worlitzsch, G. Döring, F. Meloni, K.C. Meyer, L. Dowson, S.L. Hill, R.A. Stockley, M. Luisetti. CERS Journals Ltd 2000.

ABSTRACT: Degradation of extracellular matrix components is central to many pathological features of chronic destructive lung disorders. Desmosine and isodesmosine are elastin-derived cross-linked amino acids whose urine levels are considered representative of elastin breakdown.

The aim of this study was to apply a novel methodology, based on high-performance capillary electrophoresis, to the quantification of desmosine and isodesmosine in 11 patients with stable chronic obstructive pulmonary disease (COPD), 10 with an exacerbation of COPD, nine with $\alpha_{1}$-antitrypsin deficiency, 13 with bronchiectasis, and 11 adults with cystic fibrosis, in comparison to 24 controls.

It was found that, in patients with stable COPD, urinary desmosine levels were higher than in controls $(p=0.03)$, but lower than in COPD subjects with an exacerbation $(p \leq 0.05)$. The highest desmosine levels were found in subjects with $\alpha_{1}$-antitrypsin deficiency, bronchiectasis and cystic fibrosis $(p<0.001$ versus stable COPD). In a shortterm longitudinal study, five stable COPD patients showed a constant rate of desmosine excretion (mean coefficient of variation $<8 \%$ over three consecutive days).

In conclusion, the present method is simple and suitable for the determination of elastin-derived cross-linked amino acid excretion in urine, giving results similar to those obtained using other separation methods. In addition, evidence is presented that urinary desmosine excretion is increased in conditions characterized by airway inflammation, such as exacerbations of chronic obstructive pulmonary disease, bronchiectasis and cystic fibrosis. Results obtained in subjects with $\alpha_{1}$-antitrypsin deficiency suggest that this method might be used to evaluate the putative efficacy of replacement therapy.

Eur Respir J 2000; 15: 1039-1045.
*Dipartimento di Biochimica, **Laboratorio di Biochimica e Genetica della Clinica di Malattie dell'Apparato Respiratorio, and ***Servizio Biometria e Epidemiologia Clinica, Istituto di Ricovero e Cura a Carattere Scientifico (IRCCS) Policlinico San Matteo, Università degli Studi di Pavia, Pavia, 'Fondazione S. Maugeri, Varallo (VC), and "Hnità Operativa (U.O.) Scienze Mediche, Università di Brescia, Brescia, Italy. ${ }^{++}$Hygiene Institute, University of Tübingen, Tübingen, Germany. ${ }^{\#}$ University of Wisconsin Medical School, Madison, WI, USA. 'Dept of Medicine, Queen Elizabeth Hospital, University of Birmingham, Birmingham, UK.

Correspondence: M. Luisetti, Laboratorio di Biochimica e Genetica, IRCCS Policlinico San Matteo, Via Taramelli 5, 27100 Pavia, Italy. Fax: 390382502269

Keywords: $\alpha_{1}$-Antitrypsindeficiency, bronchiectasis, chronic obstructive pulmonary disease, cystic fibrosis, lung elastin

Received: July 131999

Accepted after revision February 242000

This work was supported by Ricerca Corrente IRCCS Policlinico San Matteo, and by Ministero della Sanità CF projects law $584 / 93$.
Chronic obstructive pulmonary disease (COPD), with or without inherited deficiency of $\alpha_{1}$-antitrypsin (AAT), disseminated bronchiectasis (Bx) and cystic fibrosis ( $\mathrm{CF})$ are destructive lung disorders characterized by chronic and irreversible airflow limitation. Irrespective of the aetiological factors implicated, there is a solid body of evidence suggesting that degradation of the extracellular matrix component, mainly elastin, due to an imbalance between proteinases and their naturally occurring inhibitors, is central to many of the pathological features of these conditions [1-4].

Excess lung elastin degradation results in the excretion of elastin-derived peptides containing desmosine (DES) and isodesmosine (IDES) in urine [5]. Since these crosslinked amino acids are unique to mature elastin, their urine levels are considered to be representative of body elastin breakdown. Urinary excretion of DES and IDES has been reported to be increased in patients with COPD, current smokers with normal lung function [6] and adults with CF [7] compared to appropriate controls.
There are two validated means of detecting DES and IDES in body fluids: a separation method, based on isotope-dilution/high - performance liquid chromatography (HPLC) [8], and a method based on radioimmunoassay (RIA) [9]. Recently, however, high-performance capillary electrophoresis (CE) (HPCE) has been applied to studying different aspects of proteinase activity [10-12]. In its micellar electrokinetic chromatographic modality, HPCE has been successfully applied to the quantification of urinary DES and IDES in both COPD patients and healthy controls [13]. Following these preliminary results, a clinical study of urinary DES and IDES determination by means of micellar electrokinetic chromatography (ME$\mathrm{KC}$ ) was planned in patients with a variety of chronic destructive lung diseases, including patients with COPD (either stable or during an exacerbation), disseminated Bx of unknown origin, pulmonary emphysema associated with inherited deficiency of AAT and CF. The results were compared with those obtained in healthy nonsmokers and smokers with normal lung function. 


\section{Materials and methods}

\section{Design of the study}

This investigation was designed as a cross-sectional study, with the exception of a short-term lungitudinal study in stable COPD (see below), of consecutive patients admitted to the authors' hospitals or followed as outpatients in specialist clinics. All individuals studied (patients and controls) gave their informed consent prior to entering the study, which was approved by the local Ethical Committees of the institutions involved.

\section{Patients}

A total of 54 individuals divided into five groups were studied. Details of the patients' characteristics are reported in table 1 .

Chronic obstructive pulmonary disease exacerbation. This group comprised 10 patients (one female and nine males) with a diagnosis of COPD made according to American Thoracic Society criteria [14]. Consecutive patients were studied when admitted with an acute exacerbation of their disease, defined as an increase in two or three of the symptoms of dyspnoea, sputum volume and/or sputum purulence (type 2 or type 1, according to ANTHONISEN et al. [15]). All patients were exsmokers, with a smoking history of $38 \pm 8$ pack-yrs (mean \pm SD). None of these patients had received antibiotics or oral corticosteroids prior to hospital admission. Urine specimens were collected during the first $24 \mathrm{~h}$ of the patients' hospital stay.

Stable chronic obstructive pulmonary disease. This group consisted of 11 male patients with COPD, diagnosed as above, who had not had an exacerbation for $\geq 3$ months preceding the study. The patients were enrolled consecutively from a rehabilitation programme. All patients were exsmokers, with a smoking history of $30 \pm 6$ pack-yrs. Five of the 11 patients were followed by sampling urine specimens from three consecutive days in a short-term longitudinal study aimed at evaluating the intrapatient daily variation in urinary DES and IDES levels.

$\alpha_{1}$-Antitrypsin deficiency. This group consisted of nine patients (two females). All had COPD related to AAT deficiency status, ascertained by serum isoelectric focusing (all subjects selected displayed the PiZ phenotype). None had received AAT replacement therapy or had a recent history of an acute exacerbation. Seven of the nine AAT deficient patients were exsmokers (six had smoked for a mean of $30 \pm 5$ pack-yrs daily and one had smoked for only 1.5 pack-yrs), and two had never smoked.

Disseminated bronchiectasis. This group consisted of 13 patients (11 females). The Bx involved more than one lung lobe and was diagnosed by bronchography or high-resolution computed tomography scan. None had an identifiable cause for their disease (serum immunoglobulin and AAT levels were normal, the sweat test was negative and there was no evidence of primary ciliary dyskinesia). Eleven of the patients were studied in the stable clinical state, although all regularly produced purulent secretions and two were admitted for an acute exacerbation. In five of the 13 patients, sputum culture showed only a mixed normal flora, whereas Haemophilus influenzae was isolated from four patients, Pseudomonas aeruginosa from three, and Branhamella catarrhalis and both $H$. influenzae and Staphylococcus aureus from one each. Seven patients had never smoked, whereas five were exsmokers and one a current smoker.

Cystic fibrosis. This group was composed of 11 patients, three females and eight males. The criteria for the diagnosis of CF were positive sweat chloride testing and typical clinical manifestations of CF. Seven of these $11 \mathrm{CF}$ patients were seen as outpatients, whereas four were hospitalized for subacute exacerbations of their lung disease and undergoing treatment with i.v. antipseudomonal antibiotics. All patients had typical bronchiectatic changes on their chest radiographs, with a mean radiograph score of $56.5 \pm 28.3$ using the University of Wisconsin scoring system, ranging from 0 (best appearance) to 100 (worst appearance) [16]. All patients but one were colonized by $P$. aeruginosa, alone (five subjects) or in combination with other pathogens ( $S$. aureus two, Aspergillus fumigatus one, $H$. influenzae one, $H$. influenzae plus $A$. fumigatus one). One patient was colonized by $S$. aureus, $H$. influenzae and $A$. fumigatus.

Controls. The control group consisted of 24 subjects recruited consecutively during a cross-sectional respiratory survey performed in Rovescala (a small rural village in the province of Pavia) [17]. Twelve of the subjects (three females) had never smoked (healthy nonsmokers), whereas 12 (10 males) were current lifelong smokers with normal lung function (smokers with normal lung function), with a smoking history of $14 \pm 8$ pack-yrs.

Table 1. - Clinical characteristics of the subjects investigated

\begin{tabular}{lccccccc}
\hline & $\begin{array}{c}\text { Healthy } \\
\text { nonsmokers }\end{array}$ & $\begin{array}{c}\text { Smokers with } \\
\text { normal lung } \\
\text { function }\end{array}$ & $\begin{array}{c}\text { Exacerbated } \\
\text { COPD }\end{array}$ & $\begin{array}{c}\text { Stable } \\
\text { COPD }\end{array}$ & $\begin{array}{c}\text { AAT } \\
\text { deficiency }\end{array}$ & Bronchiectasis & $\begin{array}{c}\text { Cystic } \\
\text { fibrosis }\end{array}$ \\
\hline Subjects $\mathrm{n}$ & 12 & 12 & 10 & 11 & 9 & 13 & 11 \\
Age yrs & $42 \pm 16(25-69)$ & $45 \pm 18(23-76)$ & $70 \pm 8(56-79)$ & $68 \pm 7(60-84)$ & $55 \pm 5(52-67)$ & $62 \pm 10(41-77)$ & $30 \pm 12(18-51)$ \\
Height cm & $170 \pm 5$ & $166 \pm 8$ & $167 \pm 4$ & $170 \pm 3$ & $170 \pm 9$ & $161 \pm 5$ & $175 \pm 9$ \\
Weight kg & $72 \pm 14$ & $67 \pm 12$ & $68 \pm 7$ & $77 \pm 10$ & $70 \pm 16$ & $67 \pm 11$ & $65 \pm 12$ \\
BMI kg.m & $24.8 \pm 4$ & $24.4 \pm 3$ & $24.2 \pm 1$ & $26.8 \pm 3$ & $24.2 \pm 4$ & $26 \pm 5$ & $21.1 \pm 3$ \\
FEV1\% pred & $101 \pm 13$ & $105 \pm 6$ & $36 \pm 11$ & $62 \pm 10$ & $29 \pm 10$ & $60 \pm 21$ & $56 \pm 33$ \\
FVC \% pred & $96 \pm 11$ & $98 \pm 6$ & $54 \pm 9$ & $71 \pm 6$ & $80 \pm 19$ & $84 \pm 27$ & $73 \pm 22$ \\
\hline
\end{tabular}

Data are presented as mean \pm SD (range). COPD: chronic obstructive pulmonary disease; AAT: $\alpha_{1}$-antitrypsin; BMI: body mass index; FEV1: forced expiratory volume in one second; FVC: forced vital capacity; \% pred: percentage of the predicted value. 


\section{Biochemical evaluation}

Chemicals. Sodium phosphate $\left(\mathrm{NaH}_{2} \mathrm{PO}_{4} / \mathrm{Na}_{2} \mathrm{HPO}_{2}^{4}\right.$; used as a background electrolyte) was purchased from Bio-Rad (Richmond, CA, USA). Doubly distilled water was obtained from a Millipore Milli-Q purification system (Millipore; Bedford, MA, USA). All other chemicals were of analytical grade and were used without further purification.

Urine collection and treatment. Urine samples were collected into sterile plastic bottles and started in the morning, until a volume of $100 \mathrm{~mL}$ was obtained, which was stored at $-20^{\circ} \mathrm{C}$ until processed. Each sample was concentrated under reduced pressure using a heated rotary evaporator $\left(50^{\circ} \mathrm{C}\right)$. A sample of urine $(0.8 \mathrm{~mL})$ was then concentrated by ultracentrifugation at $13,000 \times g$ at $20^{\circ} \mathrm{C}$ in microconcentrators Microcon 30 (Millipore), transferred to pyrex hydrolysis tubes, evaporated to dryness and hydrolysed in vacuo with $6 \mathrm{~N} \mathrm{HCl}$ for $24 \mathrm{~h}$ at $106^{\circ} \mathrm{C}$. Hydrolysed samples were lyophilized and the residue dissolved in deionized water (repeated twice in order to remove the $\mathrm{HCl}$ completely). Finally, the samples were dissolved in $0.4 \mathrm{~mL}$ distilled water and submitted to HPCE. The DES and IDES content was expressed in $\mu \mathrm{g} \cdot \mathrm{g}$ creatinine ${ }^{-1}$.

Capillary electrophoretic instrumentation and running conditions. All runs were performed using a Bio-Rad Biofocus 3000 system equipped with a high-speed ultraviolet/ visible (UV-Vis) scanning detector. Fused silica capillaries of $57 \mathrm{~cm}$ ( $50 \mathrm{~cm}$ effective length from inlet to detector $) \times 50$ $\mu \mathrm{m}$ inside diameter were obtained from Beckman (Palo Alto, CA, USA). The procedure followed was essentially as described previously [13], with one major modification. Briefly, endogenous creatinine, IDES and DES were separated using $100 \mathrm{mM}$ sodium phosphate as background electrolyte, and their quantification in each urine sample was accomplished by comparing the peak areas with those of authentic compounds. A calibration curve was obtained by applying scalar amounts of each standard to the capillary. The temperature was maintained at $15 \pm 0.1^{\circ} \mathrm{C}$ and the applied electrical potential was $1.5 \mathrm{kV}$. Samples were injected hydrodynamically for $2 \mathrm{~s}$ at $0.068 \mathrm{MPa}$ to give a volume of $\sim 18.6 \mathrm{~nL}$. Analytes were monitored simultaneously at 200 and $268 \mathrm{~nm}$, and migration was from the positive to the negative pole. Between runs, the capillary was rinsed with $0.5 \mathrm{M} \mathrm{NaOH}$ for $2 \mathrm{~min}$ followed by water for $3 \mathrm{~min}$ and electrophoretic buffer for $2 \mathrm{~min}$. A typical electrophoretogram is shown in figure 1. This method complies with the assay validation requirements of the Journal of Chromatography, Biomedical Sciences and Applications [18].

\section{Statistical analysis}

Data are presented as mean \pm SD. Differences in quantitative variables among groups were tested by one-way analyses of variance (ANOVA) adjusted for age. Relationships between urinary DES and IDES levels and pulmonary function indices were investigated by means of the Pearson correlation coefficient. A p-value of $\leq 0.05$ was taken as statistically significant. Analyses were performed with Statistica for Windows $\mathbb{R}$ ) software (StatSoft Inc., Tulsa, OK, USA). The body mass index (BMI) is the weight in kilograms divided by the square of the height in metres.

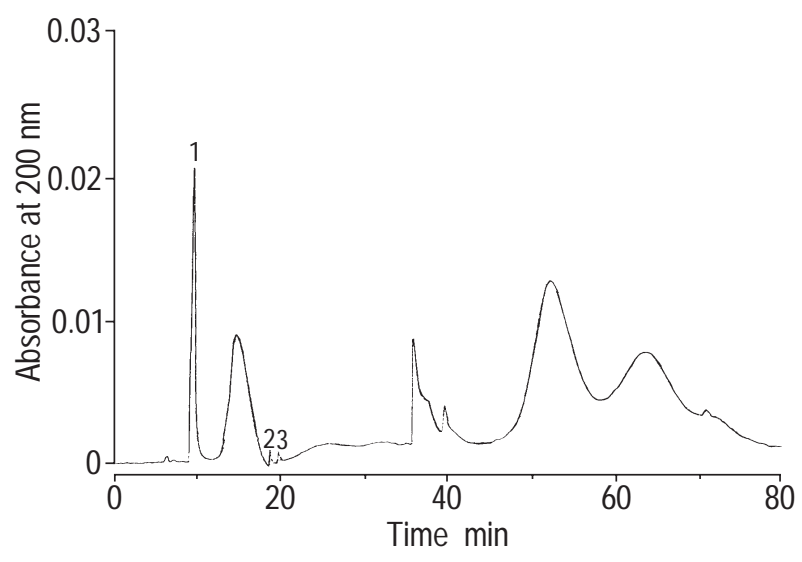

Fig. 1. - Typical electropheretogram showing the separation of creatinine (peak 1), isodesmosine (peak 2) and desmosine (peak 3) obtained under the experimental conditions described in the Capillary electrophoretic instrumentation and running conditions section.

\section{Results}

All five groups with chronic destructive lung diseases showed a significant level of lung function impairment, compared to the healthy nonsmokers and smokers (table 1). The patients with stable COPD had better lung function than those with an exacerbation (forced expiratory volume in one second (FEV1) p<0.001, forced vital capacity (FVC) $\mathrm{p}=0.027)$, although the two groups had a similar mean age (70 versus $68 \mathrm{yrs)}$ ) and smoking history. The AAT-deficient patients had worse lung function than the nondeficient COPD patients in the stable state despite their younger mean age. Their lung function was not different, however, from that in COPD patients with an exacerbation. The FEV1 of patients with disseminated Bx was similar to that of stable COPD or CF patients, and significantly higher than that of the COPD patients with an exacerbation or the AAT deficiency group $(\mathrm{p}=0.0017$ and $\mathrm{p}<0.001$, respectively). All comparisons were conducted with an adjustment for age. The mean BMI was within the desirable range (20-24.9) for most groups, although the $\mathrm{CF}$ patients tended to be at the lower end (BMI 21.1), and the stable COPD patients (BMI 26.8) and those with Bx (BMI 26) were considered to be overweight (grade 1: BMI 25-29.9).

Urinary DES and IDES excretion showed a wide range, but differed markedly between individual groups, and the interpatient coefficient of variation ranged from $15.9 \%$ for DES in smokers with normal lung function to $40 \%$ for DES in adults with CF (fig. 2). These data are summarized in table 2. In healthy nonsmokers the mean DES level was $9.31 \pm 2.75 \mu \mathrm{g} \cdot \mathrm{g}$ creatinine ${ }^{-1}$ and the mean IDES level $7.34 \pm 1.95 \mu \mathrm{g} \cdot \mathrm{g}$ creatinine $^{-1}$, whereas in smokers with normal lung function these levels were slightly but not significantly higher. All five groups with chronic destructive lung diseases, however, had significantly increased urinary DES and IDES levels. The stable COPD patients showed greater urinary DES and IDES excretion than healthy controls ( $\mathrm{p}=0.03$ and $\mathrm{p}=0.01$, respectively), whereas the DES level was higher than that in normal smokers, but this did not reach statistical significance. In contrast, the COPD patients with an exacerbation showed greater DES and IDES excretion than both the control groups, as well 
a)

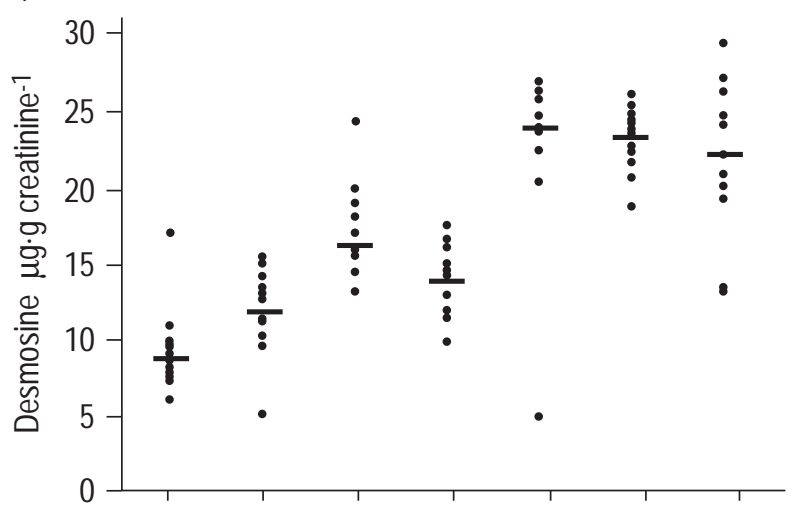

b)

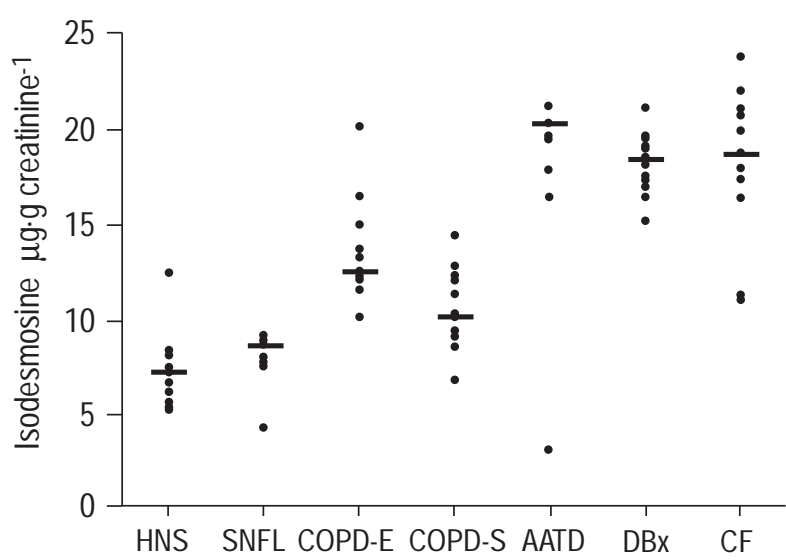

Fig. 2. - Distribution of individual levels of: a) desmosine; and b) isodesmosine in the different groups of individuals studied. Horizontal bars represent medians. HNS: healthy nonsmokers; SNLF: smokers with normal lung function; COPD-E: exacerbated chronic obstructive pulmonary disease (COPD); COPD-S: stable COPD; AATD: $\alpha_{1}$-antitrypsin deficiency; DBx: disseminated bronchiectasis; CF: cystic fibrosis.

as the patients with stable COPD. Higher DES and IDES levels than normal were also found in the remaining three groups with destructive lung diseases (Bx, AAT deficiency and CF). Only one patient with AAT deficiency had levels of DES and IDES (5.15 and $3.66 \mu \mathrm{g} \cdot \mathrm{g}$ creatinine ${ }^{-1}$, respectively) within the normal range (mean $\pm 1.96 \mathrm{SD}$ of levels in healthy nonsmokers). Among these three groups, the urinary DES and IDES levels did not differ significantly, although they were also significantly higher than those in the two groups of COPD patients (table 2).
The short-term longitudinal study, performed in five patients with stable COPD (table 3 ) showed that the mean coefficient of variation was $7.6 \%$ for DES and $7.2 \%$ for IDES.

No significant relationship between $\mathrm{FEV} 1 / \mathrm{FVC}$ ratio and DES or IDES concentration could be found in the overall group of patients with destructive lung diseases (data not shown), although a Pearson $\mathrm{r}$ of $-0.570(\mathrm{p}<$ $0.00001)$ was found for DES, and of $-0.604(\mathrm{p}<0.00001)$ for IDES when individual urine elastin breakdown marker values were analysed as a function of FEV1 (\% pred) in all subjects investigated.

\section{Discussion}

The first aim of this work was to provide evidence in addition to that in the previous report [13] that HPCE may be applied to the clinical evaluation of elastin destruction indices in chronic lung diseases. It was decided to use CE in the micellar electrokinetic chromatographic modality since the previously reported free solution CE mode of separation (capillary zone electrophoresis) of DES and IDES from hydrolysed elastin did not give satisfactory resolution of the two peaks [19]. The addition of a micellar buffer modifier such as sodium dodecyl sulphate to the background electrolyte provided enhanced resolution, thus yielding almost complete separation of the two compounds [13]. Since DES and IDES are isomers, IDES levels do not add any further information regarding elastin breakdown to that provided by DES levels. However, since peak purity (fig. 1) is one of the major criteria required for validation of the assay [18], the results of both DES and IDES determination are presented.

Results obtained by MEKC may be compared with those obtained by the isotope-dilution/HPLC method described by STONE et al. [8] since both involve separation methods. In the present study, it was found that the mean DES levels in nonsmoking controls $(9.31 \pm 2.75 \mu \mathrm{g} \cdot \mathrm{g}$ creatinine $^{-1}$ ) were only slightly higher than those found in a previous investigation $\left(7.5 \pm 1.4 \mu \mathrm{g} \cdot \mathrm{g}\right.$ creatinine $\left.^{-1}\right)$ [6], whereas the levels obtained for current smokers with normal lung function were similar $(11.97 \pm 2.75$ versus $11 \pm$ $4.2 \mu \mathrm{g} \cdot \mathrm{g}$ creatinine $\left.^{-1}\right)$. The same trend towards higher levels among COPD patients was also evident, although the levels of DES in the present series of stable COPD patients were slightly higher $(14.17 \pm 2.33 \mu \mathrm{g} \cdot \mathrm{g}$ creatinine $\left.^{-1}\right)$ than that described previously $(11.8 \pm 5.1 \mu \mathrm{g} \cdot \mathrm{g}$ creatinine $^{-1}$ ) [6].

Table 2. - Urinary desmosine (DES) and isodesmosine (IDES) concentrations in the study groups

\begin{tabular}{lccccccc}
\hline & $\begin{array}{c}\text { Healthy } \\
\text { nonsmokers }\end{array}$ & $\begin{array}{c}\text { Smokers with } \\
\text { normal lung } \\
\text { function }\end{array}$ & $\begin{array}{c}\text { Stable } \\
\text { COPD }\end{array}$ & $\begin{array}{c}\text { Exacerbated } \\
\text { COPD }\end{array}$ & $\begin{array}{c}\text { AAT } \\
\text { deficiency }\end{array}$ & Bronchiectasis & $\begin{array}{c}\text { Cystic } \\
\text { fibrosis }\end{array}$ \\
\hline $\begin{array}{c}\text { DES } \mu \mathrm{g} \cdot \mathrm{g} \\
\text { creatinine }\end{array}$ & $9.31 \pm 2.75$ & $11.97 \pm 2.75$ & $14.17 \pm 2.33^{\#}$ & $17.15 \pm 3.42^{*, 5,+}$ & $22.3 \pm 7.74 * *, * * *$ & $23.39 \pm 2.05^{\dagger, * * *}$ & $23.39 \pm 2.02^{\# \#, * * *}$ \\
$\begin{array}{c}\text { IDES } \mu \mathrm{g} \cdot \mathrm{g} \\
\text { creatinine }\end{array}$ & $7.34 \pm 1.95$ & $8.08 \pm 1.28$ & $10.59 \pm 2.17^{+,++}$ & $13.67 \pm 2.87^{*, 5,+}$ & $17.4 \pm 5.58^{* * * * * *}$ & $18.21 \pm 1.55^{\dagger, * * *}$ & $18.14 \pm 4.11^{\# \#, * * *}$ \\
\hline
\end{tabular}

Data are presented as mean $\pm \mathrm{SD}$. Differences between groups were tested by one-way analysis of variance adjusted for age. COPD: chronic obstructive pulmonary disease; AAT: $\alpha_{1}$-antitrypsin. ${ }^{*}: \mathrm{p}<0.05$ versus stable COPD; ${ }^{+}: \mathrm{p}=0.048$ versus normal smokers; ${ }^{++}$: $\mathrm{p}=0.011$ versus nonsmokers; **: $\mathrm{p}<0.01$ versus exacerbated COPD; ${ }^{*}: \mathrm{p}=0.003$ versus healthy nonsmokers; ${ }^{\# \#}: \mathrm{p}<0.003$ versus exacerbated COPD; ${ }^{\S}$ : $\mathrm{p}<0.002$ versus normal smokers; ${ }^{\dagger} \mathrm{p}<0.001$ versus healthy nonsmokers; ${ }^{\dagger}: \mathrm{p}<0.001$ versus exacerbated COPD; $* * *$ : $<<0.001$ versus healthy nonsmokers, normal smokers and stable COPD. 
Table 3. - Daily fluctuation in urinary desmosine (DES) and isodesmosine (IDES) levels in five stabe chronic obstructive pulmonary disease patients

\begin{tabular}{|c|c|c|c|c|c|c|c|c|}
\hline \multirow[t]{2}{*}{ Patient No. } & \multicolumn{3}{|c|}{ DES $\mu \mathrm{g} \cdot \mathrm{g}$ creatinine $^{-1}$} & \multicolumn{3}{|c|}{ IDES $\mu \mathrm{g} \cdot \mathrm{g}$ creatinine ${ }^{-1}$} & \multicolumn{2}{|c|}{$\mathrm{CV}$} \\
\hline & Day 1 & Day 2 & Day 3 & Day 1 & Day 2 & Day 3 & DES & IDES \\
\hline 1 & 15 & 14.2 & 15.2 & 12.22 & 11.5 & 12.61 & 2.75 & 4.62 \\
\hline 2 & 31 & 31.9 & 29.5 & 25.36 & 26.3 & 23.89 & 3.92 & 4.76 \\
\hline 3 & 21.9 & 20.4 & 19 & 17.08 & 16.99 & 16.55 & 7.1 & 1.65 \\
\hline 4 & 18.03 & 26.1 & 25.8 & 14.82 & 20.88 & 20.38 & 19.6 & 17.9 \\
\hline 5 & 26.2 & 27.3 & 28.8 & 21.03 & 21.56 & 23 & 4.73 & 4.98 \\
\hline
\end{tabular}

CV: coefficient of variation.

In stable COPD patients, there was evidence that urinary excretion of DES and IDES is relatively constant, with a mean intrapatient coefficient of variation of $<8 \%$ in five subjects on three consecutive days (table 3 ). This would suggest that, in the absence of an acute exacerbation, spot determinations of elastin-derived cross-linked amino acid excretion are likely to be representative of basal elastin breakdown.

The present series and that of STONE et al. [7] yielded identical mean urinary DES and IDES levels (23 and 18 $\mu \mathrm{g} \cdot \mathrm{g}$ creatinine ${ }^{-1}$, respectively) in adults with $\mathrm{CF}$, although the range observed for DES and IDES levels in the series of STONE et al. [6] was much greater (the SDS were 30.7 and $22.4 \mu \mathrm{g} \cdot \mathrm{g}$ creatinine $^{-1}$ for DES and IDES, respectively) compared to the current study (2.02 and $4.11 \mu \mathrm{g} \cdot \mathrm{g}$ creatinine $^{-1}$, respectively). This difference might reflect the degree of lung inflammation in the patients in the two series, as suggested by others [20].

Both the micellar electrokinetic chromatographic modality of HPCE and isotope-dilution/HPLC are separation methods for the detection of elastin-derived cross-linked amino acids and, in spite of understandable differences due to patient selection and characteristics; urine volumes and treatments; and intrinsic technical properties, seem to give similar results. The present method, like the isotope-dilution/HPLC method, is quite labour-intensive and thus difficult to transfer to a routine clinical laboratory [21]. However, an advantage of MEKC is that it is an automated process, in the course of which a large number of samples and endogenous creatinine (as internal standard) together with elastin-derived cross-linked amino acids can be analysed in a single run [13].

The second aim of the present work was to evaluate urinary DES and IDES excretion in conditions not investigated previously. First, COPD patients with exacerbations excrete more elastin-derived cross-linked amino acids than patients with stable COPD. This probably reflects the increased burden of neutrophils within the lungs occurring during an acute exacerbation of COPD [22], which is responsible for the purulence of the sputum and the high concentration of sputum serine proteinases such as neutrophil elastase [23]. Thus, it may be supposed that the increased DES and IDES excretion in an exacerbation of COPD is the result of acute damage to elastin in bronchial and bronchiolar walls by neutrophil elastase, adding to the "baseline" elastin degradation found in stable COPD (table 2, fig. 2). The two COPD populations in the present study did not differ in terms of age or smoking history, although a significantly lower level of respiratory function was found in the group with the exacerbation (table
1). However, as this was a cross-sectional study, it is likely that this difference was due to the increased pulmonary inflammation during the acute exacerbation [24]. Further studies after the resolution of the exacerbation may resolve this issue. However, it should be noted that the increased levels of DES and IDES excretion during the exacerbation are similar to those for the $\mathrm{CF}$ and $\mathrm{Bx}$ patients in the stable state, in whom the neutrophil burden is also markedly increased [25, 26], although lung function is better (table 1).

AAT deficiency, however, is another condition in which high levels of DES and IDES excretion were found in the present study. An early report failed to demonstrate increased excretion of DES (detected by a modified RIA) in the urine of PiZ subjects with emphysema [27], although subsequently the isotope-dilution/HPLC method provided preliminary evidence, in 28 AAT-deficient subjects, that urinary DES rises to approximately the same level as that found in common COPD [28]. In the present series, only one AAT-deficient patient had a urinary level of elastin-derived cross-linked amino acids within the normal range, whereas in the remainder the levels were markedly higher than even the COPD (non-AAT-deficient) patients, both in the stable state and during an exacerbation. This feature is consistent with extensive ongoing destruction of the lung parenchyma, as supported by the more severe lung function impairment and younger age of the AATdeficient patients, and probably reflects a marked disturbance in the balance between proteinases and proteinase inhibitors in the lung [2].

The relevance and clinical usefulness of elastin destruction indices is worthy of further comment. The current state of knowledge in this area has meant that there has been uncertainty as to whether urinary DES and IDES levels could be used as predictive markers of the development of pulmonary emphysema. Urinary DES levels were not found previously to be related to the FEV1 [29], and this is consistent with the current studies, in which the DES and IDES levels in the obstructed subjects did not relate to the degree of obstruction (FEV1/FVC). However, in the only longitudinal study available, a significant correlation was found between urinary DES levels and FEV1 decline in smokers, irrespective of computed tomographic evidence of emphysema [30]. This evidence, together with the present data showing that DES and IDES levels are elevated in patients with airway disease, including $\mathrm{CF}, \mathrm{Bx}$ and exacerbated COPD, would suggest that these markers reflect, at the biochemical level, an accelerated breakdown of elastin occurring either in the lung parenchyma or in the airways when inflammation is increased (a 
phenomenon not easily quantified by lung function indices or computed tomographic score). With these considerations in mind, it is most likely that the ideal application of these markers would be in clinical trials aimed at evaluating treatments specifically designed to reduce the elastase load in chronic lung disease [31]. It is likely that direct indices of the breakdown of elastin, a major target for elastase, are the most specific surrogate markers relevant to short-term trials to demonstrate the efficacy of drugs designed to reduce lung elastase burden [31, 32]. This strategy has been used in several studies to date [3336], and, interestingly, one of these studies has provided preliminary evidence in two subjects with severe AAT deficiency that AAT augmentation therapy may reduce DES and IDES excretion [36].

Thus the use of elastin-derived cross-linked amino acid analysis seems to be a reasonable means of testing the efficacy of an elastase inhibitor in a short-term and relatively feasible study. Data reported here showing high levels of desmosine and isodesmosine in $\alpha_{1}$-antitrypsindeficient subjects provide a baseline for the assessment of the putative efficacy of replacement therapy aimed at reducing elastin breakdown.

Acknowledgements. The skillful assistance of M. Malerba and L. Corda is gratefully acknowledged.

\section{References}

1. Snider GL. Emphysema: the first two centuries - and beyond. A historical overview, with suggestions for future research: part 2. Am Rev Respir Dis 1992; 146: 16151622.

2. McElvaney NG, Birrer P, Chang-Stroman LM, Crystal RG. Neutrophils, neutrophil elastase and the fragile lung: the pathogenesis and therapeutic strategies relating to lung derangement in the common hereditary lung disorders. In: Grassi C, Travis J, Casali L, Luisetti M, eds. Biochemistry of Pulmonary Emphysema. London, Springer-Verlag, 1992; pp. 169-187.

3. Stockley RA, Hill SL, Burnett D. Proteinases in chronic lung infection. Ann N Y Acad Sci 1991; 624: 257-266.

4. Döring G. The role of neutrophil elastase in chronic inflammation. Am J Respir Crit Care Med 1994; 150: S114-S117.

5. Goldstein RA, Starcher BC. Urinary excretion of elastin peptides containing desmosine after intratracheal injection of elastase in hamsters. J Clin Invest 1978; 61: 12861290.

6. Stone PJ, Gottlieb DJ, O'Connor GT, et al. Elastin and collagen degradation products in urine of smokers with and without chronic obstructive pulmonary disease. $\mathrm{Am} \mathrm{J}$ Respir Crit Care Med 1995; 151: 952-959.

7. Stone PJ, Konstan MW, Berger M, Dorkin HL, Franzblau C, Snider GL. Elastin and collagen degradation products in urine of patients with cystic fibrosis. Am J Respir Crit Care Med 1995; 152: 157-162.

8. Stone PJ, Bryan-Rhadfi J, Lucey EC, et al. Measurement of urinary desmosine by isotope dilution and high performance liquid chromatography. Correlation between elastase-induced air-space enlargement in the hamster and urinary desmosine. Am Rev Respir Dis 1991; 144: 284 290.

9. Starcher B, Scott M. Fractionation of urine to allow desmosine analysis by radioimmunoassay. Ann Clin Biochem 1992; 29: 72-78.

10. Iadarola P, Lungarella G, Martorana PA, et al. Lung injury and degradation of extracellular matrix components by Aspergillus fumigatus serine proteinase. Exp Lung Res 1998; 24: 233-251.

11. Viglio S, Zanaboni G, Luisetti M, Cetta G, Guglielminetti M, Iadarola P. Micellar electrokinetic chromatography: a convenient alternative to colorimetric and high performance liquid chromatography detection to monitor protease activity. Electrophoresis 1998; 19: 2083-2089.

12. Viglio S, Luisetti M, Zanaboni G, et al. Simultaneous determination of Pseudomonas aeruginosa elastase, human leukocyte elastase and cathepsin G activities by micellar electrokinetic chromatography. $J$ Chromatogr A 1999; 846: 125-134.

13. Viglio S, Zanaboni G, Luisetti M, et al. Micellar electrokinetic chromatography for the determination of urinary desmosine and isodesmosine in patients affected by chronic obstructive pulmonary disease. $J$ Chromatogr B Biomed Sci Appl 1998; 714: 87-89.

14. American Thoracic Society. Standards for the diagnosis and care of patients with chronic obstructive pulmonary disease. Am J Respir Crit Care Med 1995; 152: S78S121.

15. Anthonisen NR, Manfreda J, Warren CPW, Hershfield ES, Harding GKM, Nelson NA. Antibiotic therapy in exacerbations of chronic obstructive pulmonary disease. Ann Intern Med 1987; 106: 196-204.

16. Weatherly MR, Palmer CGS, Peters ME, et al. Wisconsin cystic fibrosis chest radiograph scoring system. Pediatrics 1993; 91: 488-495.

17. Meloni F, Ballabio PC, Pistorio A, et al. Urinary levels of bombesin-related peptides in a population sample from Northern Italy: potential role in the pathogenesis of chronic obstructive pulmonary disease. Am J Med Sci 1998; 315: 258-265.

18. Linder W, Waimer IW. Validated assays in the Journal of Chromatography B: an initial editorial position. J Chromatogr B Biomed Sci Appl 1986; 683: 133-134.

19. Giumelly P, Botton B, Friot R, Prima-Putra D, Atkinson J. Measurement of desmosine and isodesmosine by capillary zone electrophoresis. J Chromatogr A 1995; 710: 357-360.

20. Starcher B, Green M, Scott M. Measurement of urinary desmosine as an indicator of acute pulmonary disease. Respiration 1995; 62: 252-257.

21. Rosenbloom J. Biochemical/immunologic markers of emphysema. Ann N Y Acad Sci 1991; 624S: 7-12.

22. Selby C, Drost E, Wraith PK, McNee W. Neutrophil traffic through the lungs in man. Ann N Y Acad Sci 1991; 624: 353-354.

23. Stockley RA, Burnett D. $\alpha_{1}$-Antitrypsin in infected and non-infected sputum. Am Rev Respir Dis 1979; 120: 1081-1086.

24. Murphy TF, Sethi S. Bacterial infection in chronic obstructive pulmonary disease. Am Rev Respir Dis 1992; 146: $1067-1083$.

25. Mikami M, Llewellyn-Jones C, Bayley D, Hill SL, Stockley RA. The chemotactic activity of sputum from patients with bronchiectasis. Am J Respir Crit Care Med 1998; 157: 723-728.

26. Stockley RA, Hill SL, Morrison HM, Starkie CM. Elastolytic activity of sputum and its relation to purulence 
and to lung function in patients with bronchiectasis. Thorax 1984; 39: 408-413.

27. Pelham F, Wewers M, Crystal RG, Buist AS, Janoff A. Urinary excretion of desmosine (elastin cross-links) in subjects with PiZZ alpha-1-antitrypsin deficiency, a phenotype associated with hereditary predisposition to pulmonary emphsyema. Am Rev Respir Dis 1985; 132: 821-823.

28. Anonymous. $\alpha_{1}$-Antitrypsin deficiency: memorandum from a WHO meeting. WHO Bull 1997; 75: 397-415.

29. Davies SF, Offord KP, Brown MG, Campe H, Niewoehner D. Urine desmosine is unrelated to cigarette smoking or to spirometric function. Am Rev Respir Dis 1983; 128 : 473-475.

30. Gottlieb DJ, Stone PJ, Sparrow D, et al. Urinary desmosine excretion in smokers with and without rapid decline of lung function. The Normative Aging Study. Am J Respir Crit Care Med 1996; 154: 1290-1295.

31. Snider GL, Stone PJ, Lucey EC. The specific treatment of emphysema. Eur Respir J 1990; 3: Suppl. 9, 23s-28s.
32. Fleming TR, DeMets DL. Surrogate end points in clinical trials: are we being misled? Ann Intern Med 1996; 125 : 605-613.

33. Cohen AB, Girard W, Mclarty J, et al. A controlled trial of colchicine to reduce the elastase load in the lungs of cigarette smokers with chronic obstructive pulmonary disease. Am Rev Respir Dis 1990; 142: 63-72.

34. Cohen AB, Girard W, Mclarty J, et al. A controlled trial of colchicine to reduce the elastase load in the lungs of excigarette smokers with chronic obstructive pulmonary disesae. Am Rev Respir Dis 1991; 143: 1038-1043.

35. Luisetti M, Sturani C, Sella D, et al. MR889, a neutrophil elastase inhibitor, in patients with chronic obstructive pulmonary disease: a double-blind, randomized, placebo-controlled clinical trial. Eur Respir J 1996; 9: 1482 1486.

36. Stone PJ, Morris TA III, Franzblau C, Snider GL. Preliminary evidence that augmentation therapy diminishes degradation of cross-linked elastin in alpha-1-antitrypsin deficient humans. Respiration 1995; 62: 76-79. 